\title{
MOBILE POSITIONING FOR TRAFFIC STATE ACQUISITION
}

\author{
K. Ramm*, V. Schwieger \\ Universität Stuttgart, Institute for Applications of Geodesy to Engineering, Prof. Dr.-Ing. W. Möhlenbrink, \\ 70174 Stuttgart, Germany - (katrin.ramm, volker.schwieger)@iagb.uni-stuttgart.de
}

KEY WORDS: Mobile phones, positioning, low cost technology, traffic state acquisition

\begin{abstract}
:
The topics presented in this paper regard the project "Data Optimisation for integrated Telematics" (Do-iT) granted by the German ministry of economics and technology. Within this project the current traffic state will be derived by use of network-based data from numerous mobile phones of anonymous drivers. With regard to traditional methods like local loop data and GPS-based floating car data (FCD) this method (floating phone data, FPD) will take advantage of the area-wide availability without additional infrastructure and costs. The Timing Advance (TA) value to the serving antenna and signal strength measurements to the serving antenna as well as the six neighbouring antennas are available in the GSM network. The TA value is used to determine the distance from the serving antenna to the mobile phone. From this a search area is generated. The position of the mobile phone is determined by use of the signal strengths which are matched to a signal strength map. These positions are referenced to the digital road network. Positioning is used to enable a reliable traffic prediction as base for modern traffic control and management.

Within the paper a brief overview about the project is given. Main focus is on the positioning methods. Different approaches from least squares adjustment and Kalman filtering are presented and first results from data measured in the vicinity of Stuttgart are shown.
\end{abstract}

\section{KURZFASSUNG:}

Das in diesem Beitrag behandelte Themenfeld wird in dem Projekt „Datenoptimierung für integrierte Telematik“ (Do-iT) bearbeitet, das vom Bundesministeriun für Wirtschaft und Technologie gefördert wird. Ziel des Projekts ist die Erfassung der aktuellen Verkehrslage mit Hilfe von netzwerk-basierten Mobilfunkdaten anonymisierter Verkehrsteilnehmer. Andere Verfahren weisen gegenüber diesem Ansatz verschiedene Beschränkungen auf: Die Verkehrslageerfassung aus Schleifendaten ist auf einzelne Hauptverkehrsbereiche begrenzt und verursacht infrastrukturelle Kosten; die GPS-basierte Verkehrslageerfassung (floating car data, FCD) setzt die Kommunikation des ausgestatteten Teilnehmers über das Mobilfunknetz in eine Zentrale voraus, was ebenfalls mit zusätzlichen Kosten verbunden ist. Demgegenüber sind die in diesem Projekt verwendeten Daten (floating phone data, FPD) flächendeckend ohne weitere infrastrukturelle Maßnahmen im Mobilfunknetz verfügbar. Die für jeden Mobilfunkteilnehmer verfügbaren Daten wie der Timing Advance Wert der bedienenden Zelle und die Signalstärke zu den Nachbarzellen werden verwendet, um die Position des Teilnehmers auf der Grundlage einer Signalstärkenkarte zu bestimmen. Die erzeugten Positionen werden auf das digitale Straßennetz referenziert und für die Verkehrslageerfassung und -prognose als Basis eines modernen Verkehrsmanagements genutzt.

Der vorliegende Beitrag legt - nach einem kurzen Überblick über das Projekt - den Schwerpunkt auf die Verfahren zur Positionsbestimmung. Verschiedene Ansätze der Ausgleichungsrechung und der Kalman-Filterung werden vorgestellt. Erste Ergebnisse von Messdaten aus der Umgebung von Stuttgart werden gezeigt.

\section{INTRODUCTION}

The topics presented in this paper are a part of the project "Data Optimisation for Integrated Telematics" (Do-iT). This project is granted by the German ministry of economics and technology and deals with the acquisition of the current traffic state by use of information generated by mobile phones. Therefore network-based data of the GSM network from numerous mobile phones of anonymous drivers are recorded and evaluated. Main advantage of this method, called floating phone data (FPD), against others is its area-wide availability without additional infrastructure and costs. For example local loop data are limited to important traffic junctions; GPS-based floating car data (FCD) are yet not widespread and will potentially never be since the user has to communicate his position via the GSM network with extra costs. The current state of the project regarding mobile positioning as the basis for traffic state acquisition is presented here. Further information about the project Do-iT can be found in Wiltschko et al. (2006) and at (mar. 2007): http://www.vm2010.de/web/de/projekte/doit.html.

\section{TRAFFIC STATE ACQUISITION}

Main focus within the project is to improve the acquisition and prediction of traffic state on and off federal motorways. The traffic state should not only be monitored for selected traffic junctions but for the whole road network. The use of networkbased GSM data comprises high potential, since almost everyone has a mobile phone and in contrast to GPS these data are also available in downtown areas. The reduced accuracy of mobile positioning in comparison to GPS positioning is compensated by the high amount of data.

Two kinds of traffic state information will be generated: Short term information regarding the current traffic state to enable

\footnotetext{
* Corresponding author
} 
interventions in real-time, for example by recommendations of alternatives routes. And second the generation of so called origin-destination matrices to determine general travel behaviour during a given time span. More information can be found in e.g. Fastenrath (2007).

\section{GSM NETWORK}

\subsection{Configuration and Data of GSM Network}

3.1.1 Elements of GSM Network: The GSM network is divided into three subsystems (Roth, 2002):

- Operation and Maintenance Subsystem

- Mobile Switching and Management Subsystem

- $\quad$ Base Station Subsystem (BSS)

Main focus here is on the latter since it connects the participating mobile stations with the GSM network. Core of the BSS are the base transceiver stations (BTS) which enable communication between mobile stations (MS). Each BTS represents one cell within the GSM network and each mobile station is logged in such a cell. This is its so called serving cell. If the connection quality is higher in a neighbouring cell, because the mobile station is moving or the serving cell is overloaded, the mobile station is logged into another cell. This procedure is termed handover. Several BTS are managed by a base station controller (BSC). This is a very important point for network-based positioning, because the so called Abis interface between BTS and BSC can be used to get measurement data generated within the GSM network (compare figure 1).

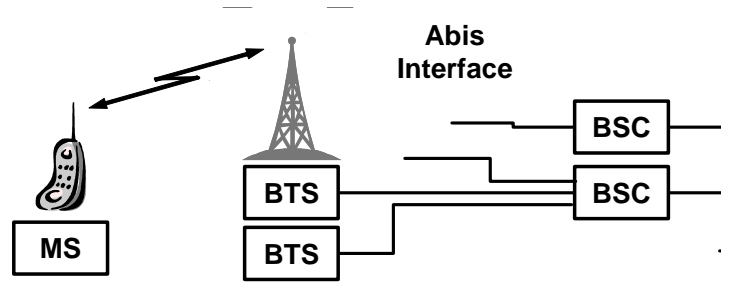

Figure 1. Abis interface within GSM network

These dynamic measurement data are described in chapter 3.2.1 and 3.2.2. They are available for purpose of operation, optimisation and administration of the GSM network and can be used for positioning additionally. For each BTS static data like the unique Cell-Identification (CI), its position, frequency and transmitter power etc. are known.

3.1.2 Signal Strength Maps: The providers of GSM networks use signal strength maps for the optimisation of their GSM network. To reach uninterrupted communication, this includes e.g. the planning of new BTS sites, the regulation of transmitter power and the adjustment of antenna orientation. These maps are generated using models that describe the attenuation of the transmitter power with regard to the surrounding environment. Such a signal strength map is available for each BTS. The attenuation of the transmitter power may result in a signal strength pattern like it is shown in figure 2 .

The signal strengths may be given in a grid of different size. For these investigations the size is approx. $150 \mathrm{~m}$ x $150 \mathrm{~m}$.

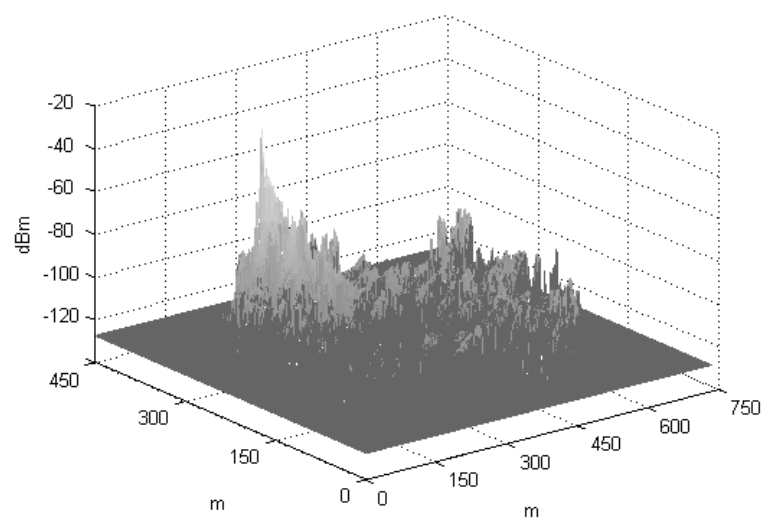

Figure 2. Example for transmitter power attenuation

\subsection{Measurements within GSM Network}

3.2.1 Timing Advance Value: To establish communication between BTS and MS, time slots are used. These time slots have to be exactly synchronised. To achieve this synchronisation, the signal propagation delay has to be taken into account (Roth, 2002). This is ensured by the timing advance (TA) value, that is an estimation for the distance between MS and the serving cell. The TA value indicates the time delay for the MS to send one data packet and is given with a resolution of approx. $550 \mathrm{~m}$. The accuracy for determination of the distance is limited to approx. $1100 \mathrm{~m}$ and depends on the distance between MS and BTS. It increases with approach to the BTS (Wiesmann, 2000). The measurement of the TA value is system intrinsic, therefore it enables network-based positioning (Reed et al., 1998).

3.2.2 Signal Strength: The received signal strength at the mobile station is an important information for handover decisions and other purposes of network optimisation and administration. Therefore the MS can measure the signal strength of the serving cell and up to six neighbouring BTS. The MS transmits these measurements to the network during communication (Walke, 2001).

The accuracy of the signal strength is subject to fluctuations, since it depends on multipath propagation, shadowing effects (moving and fixed objects) and short-term-/fast fading and is thereby related to the conditions regarding LOS (Line of Sight) respectively NLOS (Non-line of Sight) (Wiesmann, 2000). The signal attenuation is also effected by changing environmental conditions like rain, snow, humidity and temperature (Kriegl, 2000).

The signal strength is measured between $-110 \mathrm{dBm}$ and - $48 \mathrm{dBm}$. The unit $\mathrm{dBm}$ is transmission power related to $1 \mathrm{~mW}$ (Detlefsen/Siart, 2005). It holds:

Transmission power [Watt $]=10^{\frac{\mathrm{dBm}}{10}} \cdot 0,001$
Transmission level $[\mathrm{dBm}]=10 \cdot \log \left(\frac{\mathrm{Watt}}{0,001}\right)$

The difference of two transmission levels given in $\mathrm{dBm}$ results in a dimensionless relation given in decibel. The theoretical accuracy for the signal strength is given with $4 \mathrm{~dB}$ (up to -70 $\mathrm{dBm}$ ) respectively $6 \mathrm{~dB}$ (Walke, 2001). The accuracy decreases with increasing distance, i.e. the standard deviation gets higher. 


\section{POSITIONING METHODS}

\subsection{Concept}

Main objective within the project is the generation of traffic state information. To achieve a dense coverage of the whole road network, one can benefit from the high amount of data available in the GSM network. In this context it is neccessary to classify each participant in the GSM network if she/he is a driver or not and to relate the positions of the classified participants to the road network. This classification is not treated in this paper, but in Schollmeyer / Wiltschko (2007). Here the following two processing steps are shown:

- Positioning by use of measurements within GSM network

- Referencing these positions to the road network Different approaches to achieve this have been developed, realised and tested. A first approach is described in Ramm et al., (2006). It deals with adjustment of arc sections. Therefore, the measured signal strengths are transformed in distances via attenuation models. In this paper an approach without transformation of the signal strengths is shown. Instead, the measured signal strengths are directly matched into their corresponding signal strength maps, compare chapter 3.1.2. Subsequently the determined trajectories are referenced to the road network. The first is described in detail, the latter briefly in the following.

\subsection{Matching to Signal Strength Map}

The matching procedure comprises a least squares adjustment in the first step. The resulting positions are then introduced into a Kalman filter. Both methods of mobile positioning are shown in the following.

4.2.1 Least squares adjustment: The matching to a signal strength map was realised following Hellebrandt et al. (1997), Hellebrandt/Mathar (1999) and Catrein et al. (2004). For each epoch, in which measurements for one participant are available, a matching to the signal strength map has to be done. Prerequisite is the generation of an appropriate search area, which restricts the whole area to the most probable one. This can be achieved by use of the serving cell information. The TA value measured and the transmitting direction $\varphi$ of the BTS are used to determine a position via polar survey from the BTS position (compare figure 3).

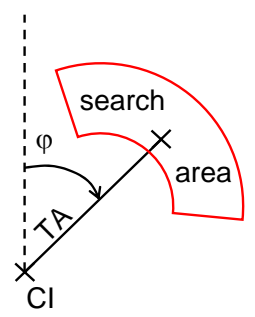

Figure 3. Generation of search area

This position is surrounded by the search area. Its widths depends on the uncertainty of the TA value and the apex angle is given by the sector size of the cell. This search area is up to now approximated by a rectangle and is transformed within the signal strength map of each measured neighbouring BTS. The reference signal strengths within the search area are extracted and compared with the corresponding measured signal strength.
This leads to an array of deviations for every BTS. Each element of these arrays is quadratically sumed up with its corresponding elements of all BTS. The position of the MS is the one with the smallest sum:

$$
\min _{y, x \in A} \sum_{i=1}^{n}\left(r x_{r e f}(y, x)_{i}-r x_{\text {meas }, i}\right)^{2}
$$

with

$$
\begin{array}{ll}
A: & \text { search area } \\
n: & \text { number of measured neighbouring cells } \\
r x_{\text {ref }, i}: & \text { reference signal strength of BTS } i \text { depending on }(y, x) \\
r x_{\text {meas }, i}: \text { measured signal strength of BTS } i
\end{array}
$$

This procedure is repeated for every measurement epoch of one participant, thus generating a trajectory. This trajectory can further be improved by smoothing and/or Kalman filtering. Smoothing is done by a moving average filter with an empirically determined lengths of $13 \mathrm{~s}$.

4.2.2 Kalman filter: For the Kalman filter a simple model is introduced. Estimates are position $(y, x)$ and velocity $\left(v_{y}, v_{x}\right)$. The model descibes a uniform motion

$$
\left|\begin{array}{c}
x_{k+1} \\
y_{k+1} \\
v_{x, k+1} \\
v_{y, k+1}
\end{array}\right|=\left|\begin{array}{cccc}
1 & 0 & \Delta t & 0 \\
0 & 1 & 0 & \Delta t \\
0 & 0 & 1 & 0 \\
0 & 0 & 0 & 1
\end{array}\right| \cdot\left|\begin{array}{c}
x_{k} \\
y_{k} \\
v_{x} \\
v_{y}
\end{array}\right|+\left|\begin{array}{cc}
0 & 0 \\
0 & 0 \\
\Delta t & 0 \\
0 & \Delta t
\end{array}\right| \cdot \mathbf{w}
$$

where

$$
\tilde{\mathbf{x}}_{k+1}=\mathbf{T} \cdot \tilde{\mathbf{x}}_{k}+\mathbf{C} \cdot \mathbf{w}
$$

$\mathbf{T}$ is the transition matrix, $\mathbf{C}$ is the diturbance matrix and $\mathbf{w}$ is the disturbance quantity considered.

Input $\mathbf{l}_{k+1}$ are the adjusted trajectories. The measurement equation is

$$
\mathbf{l}_{k+1}=\mathbf{A} \cdot \tilde{\mathbf{x}}_{k+1}+\varepsilon_{k+1}
$$

With design matrix A

$$
\mathbf{A}=\left|\begin{array}{llll}
1 & 0 & 0 & 0 \\
0 & 1 & 0 & 0
\end{array}\right| .
$$

For further details of the Kalman filter algorithm see (Kalman, 1960).

\subsection{Reference to Road Network}

The determined trajectories have to be referenced to the road network to enable the generation of traffic state information. Since the accuracy of the procedure descibed in 4.2 is not adequate for standard map-matching algorithms considering shape or curvature (see e.g. Czommer, 2000), a different procedure is developed. According to Hofmann-Wellenhof et al. (2003) one may call it map-aiding. 


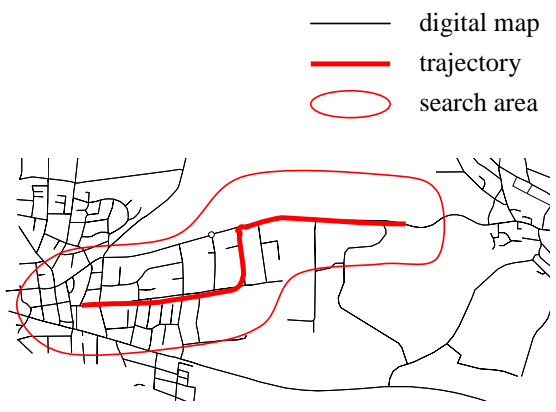

Figure 4. Search area for extraction of road elements

The trajectories are projected onto the digital road map and their uncertainty generates a search area. Whitin this search area all road elements are extracted. The accuracy of the first and the last position is used to extract start and end nodes of the digital road network. The nodes are used to determine possible routes via shortest path algorithms (Dijkstra, 1959). All possible paths are evaluated by their plumb line to the trajectory determined. The one with the smallest standard deviation is the most probable one.

\section{RESULTS}

\subsection{Matching to Signal Strength Map}

Up to now only few measurement data of the GSM network are available from the network provider. First results of a test run are shown in the following. The test run was carried out in the vicinity of Stuttgart with the measurement vehicle of the insitute. It was equipped with a mobile station, which was in active call while driving. In addition GPS positions were recorded from a Garmin eTrex Vista to generate a reference trajectory.

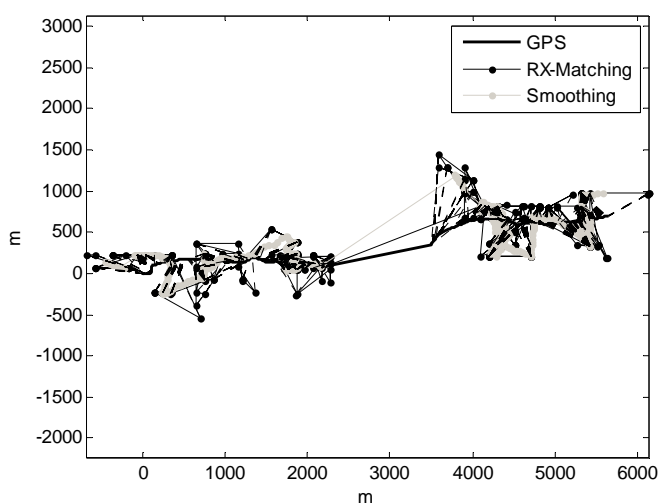

Figure 5. Results of matching to signal strength map

Results of the signal strength matching are shown in figure 5. Therein the machted positions are related to the GPS positions by dotted lines. Smoothed positions are also presented. The results of Kalman filtering for the positions from signal strength matching are shown in figure 6 .

The following measures were used to evaluate the accuracy of the positioning methods. The deviation $d_{i}$ in comparison of the MS position $\left(y_{i, M S}, x_{i, M S}\right)$ to the GPS position $\left(y_{i, G P S}, x_{i, G P S}\right)$ of every time point $i$ is

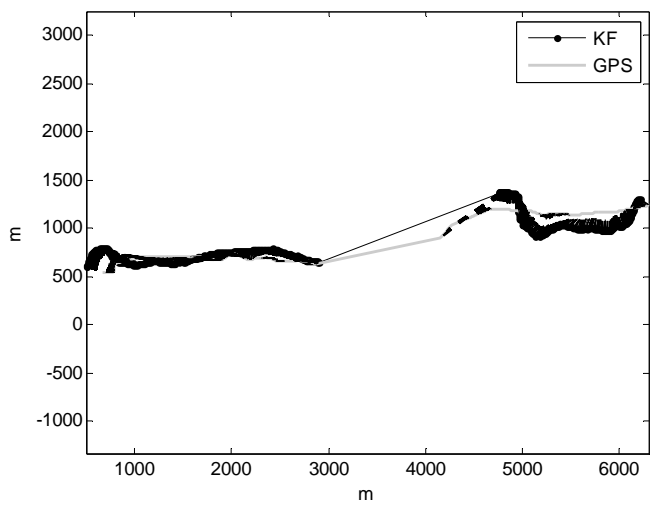

Figure 6. Results of Kalman filtering

$$
d_{i}=\sqrt{d y_{i}^{2}+d x_{i}^{2}}
$$

where

$$
\begin{aligned}
& d y_{i}=y_{i, M S}-y_{i, G P S} \\
& d x_{i}=x_{i, M S}-x_{i, G P S} .
\end{aligned}
$$

The mean deviation is given by

$$
\bar{d}=\frac{1}{n} \sum_{i=1}^{n} d_{i}
$$

and the standard deviation results in

$$
S_{d}=\sqrt{\frac{1}{n} \sum_{i=1}^{n} d_{i}^{2}} .
$$

The time-related deviation is determined to evaluate the smoothness of the trajectory:

$$
\Delta d_{i}=\sqrt{\Delta d y_{i}^{2}+\Delta d x_{i}^{2}}
$$

where

$$
\begin{aligned}
& \Delta d y_{i}=d y_{i+1}-d y_{i} \\
& \Delta d x_{i}=d x_{i+1}-d x_{i}
\end{aligned}
$$

The mean time-related deviation is given by

$$
\Delta \bar{d}=\frac{1}{n-1} \sum_{i=1}^{n-1} \Delta d_{i}
$$

and its standard deviation by:

$$
S_{\Delta d}=\sqrt{\frac{1}{n-1} \sum_{i=1}^{n-1} d_{i}^{2}} .
$$

The results for the test run shown are given in figure 7. Even the standard deviation of simple matching to the signal strength map (RX) is smaller than $350 \mathrm{~m}$. This is factor 2.5 better than the results of the postioning methods presented in Ramm et al. 
(2006). The smoothing results in further improvement (standard deviation smaller than $300 \mathrm{~m}$ ), the effect of filtering is in contrast marginal. The evaluation of the shape (standard deviation of time-related deviation) gives outstanding results, especially for the smoothed and filtered positions as it is expected from figures 5 and 6 . This is important for the possibility to applicate standard matching algorithms (digital road map) like mentioned in 4.3 in the future. Up to now the consideration of the standard deviation in equation (4) is relevant, due to the fact that map-aiding is used instead of mapmatching.

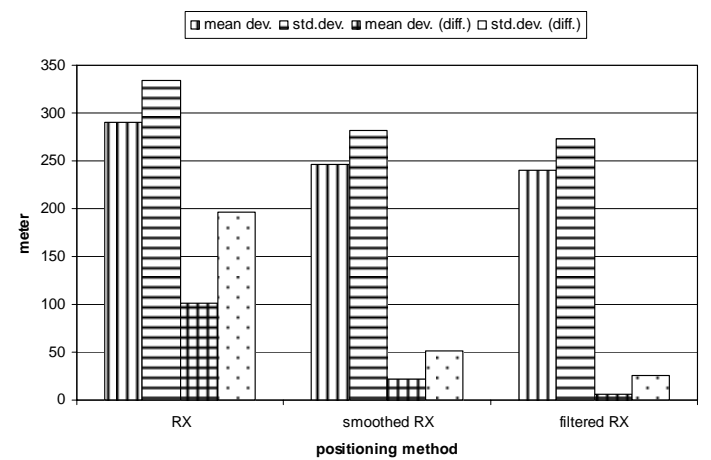

Figure 7. Achieved accuracy of test run shown

\subsection{Reference to Road Network}

The trajectory resulting from Kalman filtering as the most promising one is used to derive the reference to the road network. The search area for extraction of road data as described in 4.3 is approximated by the individual positions accuracy. It depends on the search area chosen for matching to the signal strenght map. This is expanded by an empirically chosen factor of uncertainty. The resulting search area for the test run shown is illustrated in figure 8. Using this search area road elements are extracted. For the determination of shortest paths it is necessary to define start and end nodes. This is also shown in the figure. There are 13 start nodes and 10 end nodes resulting in 130 possible routes. The procedure to further reduce these possibilities before calculation of plumb lines is not shown in detail here.

In figure 9 the resulting route is shown. It is possible to reference the correct road element, if the possible routes are distant in relation to the accuracy achieved by signal strength matching. Up to now a correct reference to a road in an urban area could not be reached. In rural areas the reference is possibile as shown in figure 9. Here the standard deviation regarding the plumb lines between filtered trajectory and most probable route is estimated to approx. $120 \mathrm{~m}$.

\section{CONCLUSION}

The use of network-based GSM data for mobile positioning is very promising regarding the possibility to derive traffic state information in suburban area. Up to now standard deviations of approx. $300 \mathrm{~m}$ are obtained for trajectories with a length of $4 \mathrm{~km}$ using matching on signal strength maps. The map-aiding procedure results in a standard deviation of approx. $120 \mathrm{~m}$ in relation to the most probable route. The presented results have to be validated by further measurement data. In urban areas further improvements are necessary for a detailled traffic analysis.
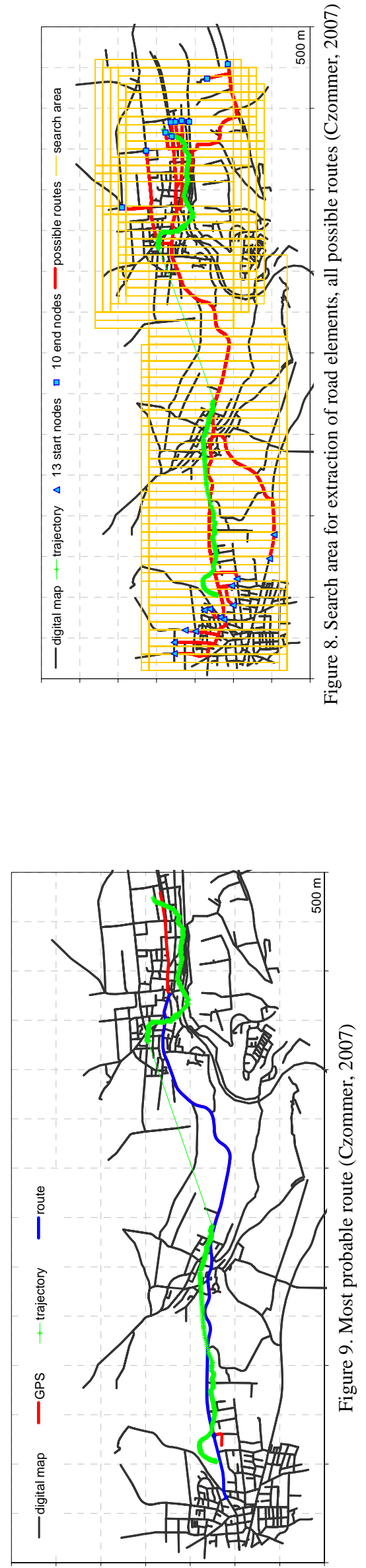


\section{Acknowledgement}

The topics presented regard the project "Data Optimisation for integrated Telematics" (Do-iT). It is granted by the German ministry of economics and technology, no. 19 B 5007.

\section{References}

Catrein, D., Hellebrandt, M., Mathar, R., Serrano, M. (2004): Location Tracking of Mobiles: A Smart Filtering Method and Ist Use in Practice. Proceedings: IEEE VTC Spring 2004, Milan May 2004, CD., p. 2677-2681.

Czommer, R. (2000): Leistungsfähigkeit fahrzeugautonomer Ortungsverfahren auf der Basis von Map-Matching-Techniken, Deutsche Geodätische Kommission Reihe C Nr.535, München, 2000.

Czommer, R. (2007): Ergebnisse der Mobilfunkortung, Teil 2. Interner Statusbericht (AP4) zum Projekt Datenoptimierung für integrierte Telematik (Do-iT), unveröffentlicht.

Detlefsen, J., Siart, U. (2003): Grundlagen der Hochfrequenztechnik, Oldenbourg Verlag, München.

Dijkstra, E.W. (1959): A note on two problems in connexion with graphs, Numerische Mathematik 1.

Fastenrath, U. (2007): Erfahrungen und Perspektiven mit Floating Car Data. Verkehrsinformation und Verkehrsmanagement im 21. Jahrhundert, 30. März 2007, Mainz.

Hellebrandt, M., Mathar, R. (1999): Location Tracking of Mobiles in Cellular Radio Networks. IEEE Transactions on Vehicular Technology, Vol. 48, No. 5, September 1999, p. 1558-1562.

Hellebrandt, M., Mathar, R., Scheibenbogen, M. (1997): Estimating Positon and velocity of Mobiles in a Cellular Radio Network. IEEE Transactions on Vehicular Technology, Vol. 46, No. 1, February 1997, p. 65-71.

Hofmann-Wellenhof, B., Legat, K., Wieser, M. (2003): Navigation. Principles of positioning and guidance. SpringerVerlag, Wien.
Jonsson, D.K., Olavesen, J. (2002): Estimated accuracy of location in mobile networks using EOTD. Master Thesis in Information and Communication Technology.

Kalman, R. E. (1960): A New Approach to Linear Filtering and Prediction Problems. Transactions of the ASME-Journal of Basic Engineering, Volume 82, Series D, p. 35-45.

Kriegl, J. (2000): Location in Cellular Networks. Automated Vehicle Monitoring based on GSM Positioning. Diploma Thesis, Institute for Applied Information Processing and Communications, University of Technology Graz, Austria.

Ramm, K., Czommer, R., Schwieger, V. (2006): Map-based Positioning using Mobile Phones. Proceedings on XXIII International FIG Congress, München, 8.-13.10.2006.

Reed, J. H., Krizman, K. J., Woerner, B. D., Rappaport, Th. S. (1998): An Overview of the Challenges and Progress in Meeting the E-911 Requirement for Location Service. In: IEEE Communications Magazine, Volume 36, Issue 4, April 1998.

Roth, M. (2002): Mobile Computing. Grundlagen, Technik, Konzepte. dpunkt Verlag, Heidelberg.

Schollmeyer, R., Wiltschko, T. (2007): Classification of public transport vehicles using cellular mobile radio data. 6th European Congress \& Exhibition on Intelligent Transport Systems and Services, ITS Aalborg 2007 Congress, Denmark, 18-20 june 2007, (accepted paper).

Walke, B. (2001): Mobilfunknetze und ihre Protokolle 1: Grundlagen, GSM, UMTS und andere zellulare Mobilfunknetze. Teubner Verlag, Stuttgart/Leipzig/Wiesbaden.

Wiesmann, R. (2000): Mehrwertdienste durch Positionsbestimmungen. Funkschau 26/2000, S.26-38.

Wiltschko, T., Schwieger, V, Möhlenbrink, W. (2006): Generating Floating Phone Data for Traffic Flow Optimization. Proceedings on 3rd International Symposium "Networks for Mobility”, Stuttgart, 5.-6.10.2006. 